\title{
Mental Health Service in Ghana: A Review of the Case
}

\author{
Samuel Adu-Gyamfi \\ Department of History and Political Studies, Kwame Nkrumah University of Science and Technology, Ghana
}

\begin{tabular}{|c|c|}
\hline Article Info & ABSTRACT \\
\hline Article history: & Mental health care in Ghana has been fraught with several challenges leading \\
\hline Received Sep 21, 2017 & $\begin{array}{l}\text { to stagnant growth in mental health service delivery and in some cases a } \\
\text { severe depreciation in the nature of care. The Government of Ghana pays }\end{array}$ \\
\hline Revised Nov 16, 2017 & little or no attention to mental health care in the country, a situation that has \\
\hline Accepted Dec 2, 2017 & $\begin{array}{l}\text { led to poor service delivery in the three major psychiatric hospitals in Ghana. } \\
\text { The implementation of the Ghana Mental Act of } 2012 \text { has also been faced }\end{array}$ \\
\hline Keyword: & $\begin{array}{l}\text { with major challenges with no significant progress being made. This study } \\
\text { therefore sought to review and document the development of mental health }\end{array}$ \\
\hline Ghana & care services in Ghana. Specifically, the study examined the various \\
\hline Mental health law & $\begin{array}{l}\text { legislations on mental health that have been enacted in Ghana since } 1900 \text {, } \\
\text { investigated the implementation of the current Mental Health Act of Ghana }\end{array}$ \\
\hline Mental health & found out whether the Ghanaian government has prioritised mental health \\
\hline Policy & service in the country and assessed the challenges and problems that \\
\hline Psychiatry & $\begin{array}{l}\text { confronted mental health service in Ghana since } 1900 \text {. The study concludes } \\
\text { that, since } 1888 \text { efforts have been made by various governments to legislate } \\
\text { the provision of mental service in Ghana. However, these legislations have } \\
\text { not always protected the rights and interest of the mentally ill. }\end{array}$ \\
\hline
\end{tabular}

Copyright $\odot 2017$ Institute of Advanced Engineering and Science. All rights reserved.

\section{Corresponding Author:}

Samuel Adu-Gyamfi,

Department of History and Political Studies,

Kwame Nkrumah University of Science and Technology,

Kumasi, Ashanti Region, Ghana

Email: mcgyamfi@yahoo.com, sadu-gyamfi.cass@knust.edu.gh

\section{INTRODUCTION}

Mental health service has become an issue worth investigating because of the number of people affected by mental disorders. Societal pressures and various issues of life have become the source of depression causing many people to have mental problems. The global incidence of mental disorders was estimated to be about 12 percent of the global burden of disease in the year 2000 [1]. The World Health Organisation estimates that globally, one out every four persons suffer from a diagnosable mental disorder the course of their lifetime. In Ghana however, there is no comprehensive data on the incidence of mental disorders. Information about the prevalence of mental disorders in Ghana is often based on estimates from the WHO or through anecdotal information. Based on the estimate from the WHO, at least 13 percent of the adult population in Ghana are likely to suffer from mental disorders, with about 3 percent suffering from severe mental illnesses [2].

Mental health care in Ghana has been fraught with several challenges leading to stagnant growth in mental health service delivery and in some cases a severe depreciation in the nature of care. Mentally ill people are some of the most vulnerable people in society. They are often subject to discrimination, social isolation and exclusion, human rights violations, and an ancient demeaning stigma which leads to removal of social support, self-reproach, or the decaying or straining of important relationships [3]. Consequences of poor mental health also include being predisposed to a variety of physical illnesses, having quality of life reduced, having fewer opportunities for income, and having lower individual productivity, which affects total national output. Poor mental health can also account for violence, drug trafficking, child abuse, paedophilia, 
suicide, crime, and other social vices [4]. Even though mental health is becoming a serious international health concern, many countries, specifically the Less Developed Countries (LDC), struggle to address the inadequate amount of resources being channelled into the provision of mental health service. Ghana does not have adequate legislations to protect the rights of people with mental disorders. There is apparently little or no implementation of the existing mental health policies.

The World Psychiatric Association (WPA) had indicated that the development of mental health in LDCs like Ghana are impeded by scarcity of resources, lack of awareness of the prevalence rate of mental illness and the social stigma associated with seeking medical care from the psychiatric hospital. Siginificantly, the kind of treatments available for mentally ill patients in Ghana is very poor. The main form of care for mental health patients is through institutional confinement with its attendant mistreatments and the curtailing of the rights of patients. This is a remnant from the colonial past of the country [5]. The WHO estimates that over two million Ghanaians are suffering from moderate to severe mental illness out of which less than two percent receive treatment from public hospitals due to inadequate facilities to admit mentally ill patients. Mental health service is under resourced in Ghana. In 2012, the Ministry of Health reports that only 3.4 percent of the total health budget was dedicated to the improvement of mental health services [6]. The underdevelopment of mental health service is even more serious when one considers the doctor-patient ratio. Currently, there is one psychiatrist per 1.5 million people in Ghana with only three major psychiatric hospitals serving the whole country. These mental health facilities are located in the southern part of Ghana. This makes mental health services inaccessible to a vast number of the Ghanaian population. This poor mental health service has caused many families to rely on traditional methods to seek health care for their mentally ill relatives which sometimes complicate the initial illness.

Irrespective of these glaring problems facing the mental health care sector, politicians and policy makers have expressed very little concern to solve the many problems facing mental health patients. Policy makers focus more on other forms of ailments to the neglect of mental health issues. The underdevelopment of mental health services has historical antecedents. In the year 1888, the then Governor of the Gold Coast, Sir Griffith Edwards promulgated the Lunatic Asylum Ordinance which encouraged the detention of mental health patients in prison in the capital city of Accra. In the year 1906, the colonial administration built a Lunatic Asylum to house the increasing insane/vagrant people. The Accra psychiatric Hospital was completed in 1951 after the successful conversion of the old prison into a hospital. This facility was the only psychiatric facility in the West African Sub-Region in the 1950s. Ghana's Mental Health Decree, which insisted on the compulsory detention of mentally sick patients did not change much over time. Mentally sick people in Ghana are still treated as if they do not have any rights at all. Although, Ghana has seen considerable changes in the provision of mental health services since 1888 , there are still lots of work that need to be done to improve the nature of health care services available to mentally ill persons in Ghana. It is based on this reason that this study has been conducted to review and make a statement on poor mental health services in Ghana since 1900.

Again, mental health service in Ghana has not been a priority for both government and health researchers. There seem to be a subtle impression that mental illness must not be discussed in public circles making its treatment as a relevant social and research problem a difficulty. Within families, people with mental disorders are often neglected and abandoned on the streets. Different government in Ghana at different times payed little or no attention to mental health care in the country, a situation that has led to poor service delivery in the three major psychiatric hospitals in Ghana. The implementation of the Ghana Mental Health Act of 2012 has also been faced with major challenges with no significant progress being made.

Also, irrespective of the obvious challenges within the mental health care system, to emphasize, researchers have not paid attention to the poor mental health services in Ghana. Historians in particular and other social scientists have not shown interest in investigating into the antecedents of this poor services delivery within the mental health system in Ghana. In the year 1972, Adomakoh, investigating into the profile of mental hospital patients remarked that, there was scanty knowledge of psychiatric illness in Ghana [7]. A careful search of mental health care studies in Ghana shows that very few researchers have interest in the field and conducted studies in that regard. Yet little or none of these researches was conducted by social historians. Significantly, the proper understanding of medical history of a patient and a particular society is about half-way to getting the health problem solved. Yet, historians and medical historians for that matter have abandoned research into mental health care services in Ghana leading to a general lack of understanding into the factors that have contributed to the poor services delivery in that sector. There is the need for accurate data on the epidemiology of mental disorders in Ghana.

The absence of reliable data and research in psychiatric studies has led to use of anecdotal evidence for policy decisions in Ghana. Mental health only became an issue in Ghana in 1945, in the then Gold Coast when the colonial masters commissioned a study into mental illness. The focus of this study was only to enumerate the number of West Africans living with any form of neurosis and psychosis. As a result, it was

IJPHS Vol. 6, No. 4, December 2017 : $299-313$ 
part of a broader West African study not just limited to Ghana. However, it was this study that drew the attention of health experts to the seriousness of mental illness in Ghana when over four hundred cases of mental disorders were identified with the help of census enumerators and village chiefs [8]. After independence, little studies have been conducted into the incidence of mental illness in Ghana by some few psychiatrists [9], which are occasionally assisted by foreign researchers [10]. It is for this reason that this historical study has been conducted to investigate the reasons for the poor state of mental health services in Ghana from 1900 to 2012 where increased public awareness drew the attention of politicians to the need to develop a new mental health legislation to address the new challenges facing people with mental disorders in Ghana. The study therefore gleans secondary information from the literature and contemporary responses to highlight the issues in contemporary times to better the lot of society and Ghana in particular.

\section{METHOD OF THE STUDY}

This study is a qualitative research. Ormston, Spencer, Barnard and Snape [11] citing Flick [12] explained qualitative research to be the naturalistic, interpretive approach, concerned with exploring phenomena from the interior and taking the perspectives and the accounts of research participants as starting points. Qualitative research design involves the use of qualitative instruments like interview schedule among others to gather data on a particular phenomenon under investigation has been found useful in this research. Qualitative data has been obtained from both primary and secondary sources. Qualitative data concerning the perceptions and attitudes of Ghanaians toward psychiatric patients were retrieved from the respondents; ten in number, three doctors who are stake holders, two other stake holders from related institutions and three psychiatry nurses who are also considered as stake holders from the Komfo Anokye Teaching Hospital (KATH), Kumasi. The responses from the severally anonymized respondents were tape recorded with permission from the concerned respondents, others were recorded in a field notebook, and this ensured consistency. Again, corpus of information was retrieved from existing literature: books, articles and relevant internet sources.The qualitative data obtained from informants from Kumasi and KATH in particular were analysed thematically by comparing the different responses in order to identify common trends, similarities and contrasts through the application of ethnography. Ethnographic analysis involves identifying categories related to a culture's economy, demographics, human life, particularly family, education, and health care issues, and the environment [13]. Specific normative and subjective statements and viewpoints from the perspective of respondents were presented through direct quotations among others.

\section{DISCUSSION}

This section discusses two themes; review of the mental health issues thus far, and responses from interviewees concerning the state of poor mental health in Ghana.

\subsection{Historical overview}

Statutory backing for institutionalisation of mental health patients started with enactment of the Asylum Ordinance in 1888 by the then Governor of the Gold Coast, Sir Griffith Edwards as a move to curb the situation where mentally ill patients were seen roaming in towns and villages causing damage to properties and sometimes inflicting harm on people [14]. The enactment of this act led to the criminalisation of insanity where people who were perceived to be mentally ill were put in prison in the capital of the Gold Coast. This special prison arrangement was under harsh conditions and the 'prisoners', who were mentally ill were put under strict restrictions [15]. By the year 1900, the special prison for housing psychiatric patients was full and new cases of mental illness could not be admitted. This necessitated the construction of an actual psychiatric hospital in the capital. Therefore in the year 1906 the first psychiatric hospital was built in the West of Africa by the British Empire. This facility was known as the "The Lunatic Asylum" [16]. From the inception of lunatic asylum in 1906 till 1950, the facility ran without a substantive psychiatrist. It was not until 1951 that a native of the Gambia, Dr. E.F.B Foster was posted by the colonial administration from London to head the psychiatric hospital in Accra [17].

The work of Dr. Foster helped to transform the delivery of mental healthcare drastically in Ghana. It was during the era of Dr. Foster that the asylum was transformed into a Hospital with a resident medical doctor based on global trends at the time. It was during his tenure that many psychiatric doctors and nurses were given training to become professionals. These doctors later became trainers themselves. Through his initiative, many psychiatric doctors were sent abroad to pursue further studies in psychiatry medicine. During the time of Dr. Foster, there was the training of Qualified Registered Mental Nurses (Q.R.M.N) in 1952 by Mrs. Higginson, a British national [18]. In the year 1963, the Ghana Medical School started with the 
inclusion of an undergraduate course in Psychiatry. The first trained mental health nurse in Ghana was Mr. L.L. Tamakloe who joined the training school in 1965 [19].

In 1983, Dr. B. Asare was appointed by the then head of state, H.E. J. J. Rawlings to be the head of Ghana Psychiatric Hospital. The appointment of Dr. Asare coupled with the interest from the Head of State in 1983, resulted in the setting up of a committee to advise the Government on improving Psychiatric Services in the country and especially in the Accra Psychiatric Hospital. This was followed by the creation of the mental health unit within the Ministry of Health. This culminated into the new era of psychiatric care in Ghana. This new era was characterised by the opening of more mental health care facilities in Ghana as well as training centres for Qualified Registered Mental Nurses in the 1900s. Public awareness of mental health issues was intensified during this era leading to the reduction of the mentally ill in institutional care from a population of 2000 to 1000 patients by the year 2000 [20].

\subsection{Legislations for mental health in Ghana}

This section studies the historical overview of legislations on mental health in Ghana over the period under review. These legislations include statute laws and government decrees concerning healthcare delivery to mental health patients.

\subsubsection{Lunatic asylum act (1888)}

This Acts encouraged the confinement of mentally ill patients to institutional care. These people were seen more of outcasts that society needed to rid itself of. This was the first Act enacted in the Gold Coast in relation to mental health in Ghana. The enactment of this act marked the beginning of formal government mental health service delivery in Ghana [21]. The Lunatic Asylum Act of 1888 treated mental illness as if it was a crime, creating a specialised prison for patients instead of seeking to cure them of the disease. During the period of operationalization of this Act, an individual lost his or her freedom upon the suspicion of mental illness. This led to a situation where families were reluctant to report cases of family members suffering from mental illness to the hospital for fear of incarceration. This law was operational in Ghana for eighty-four (84) years until 1972 when the NRC passed the Mental Health Act.

\subsubsection{The mental health decree of 1972 (NRCD 30)}

The 1972 law was considered a major improvement over the Lunatic Asylum Act of 1888. However, some elements of the 1888 Ordinance were maintained. Just like the 1888 ordinance, the Mental Health Decree of 1972 emphasized institutional care to the detriment of providing mental care in primary health care settings [22]. This provision in the Act was a contradiction to the many international treaties that Ghana had signed unto. The NRCD Decree 30 gave way for the abuse of people's freedom and liberties [5]. For instance, the procedure for involuntary admission in the 1972 Act did not sufficiently protect people against unnecessary admission. Serious mistreatments of people with mental disorders took place under this legislation with some people being locked away in institutions for decades [23]. This law was operational for forty (40) years and significantly took away the rights of people with mental disorders by seeking to keep sick people off the street as well as protect their belongings and assets. Under this law, mental health patients were not considered sane enough to enjoy basic human rights [24]. The Mental Health Decree NRCD 30 was never fully implemented.

\subsubsection{The mental health act of 2012}

In 2012, a revised Mental Health Law was passed: the Mental Health Act 846 (2012). This new Act was drafted between 2004 and 2006 with World Health Organisation (WHO) experts and consultants from South Africa, Zimbabwe, Canada, USA and Switzerland. It received presidential assent in May 2012, ready for the establishment of a Mental Health Board and production of a Legislative Instrument. It became law on 1st December 2012.

The new Law became necessary as it was recognised that the 1972 legislation, even if now fully implemented, was outdated as it no longer fell within best practices in mental health care. The new Mental Health Act focuses on improving the access to care for people with mental illness, including epilepsy capturing the challenges facing the poor and vulnerable, safeguarding human rights and promoting participation in restoration and recovery of the mentally ill. Although epilepsy is recognized in Ghana and elsewhere to be a neurological disorder rather than a mental disorder, it is treated by psychiatrists in Ghana for convenience based on shared attributes of stigma and local belief systems. The law provides for the integration and regulation of spiritual and traditional mental health practices in Ghana. It supports decentralisation of mental health care and places emphasis on community rather than institutional care [25].

The passage of the Mental Health Act 2012 by parliament in March 2012 marked a major milestone in addressing mental health as a public health issue and also in the protection of the human rights of people 
with mental disorders in Ghana [23]. The last major revision of mental health law was undertaken in the late 1960s, culminating in the enactment of the Mental Health Decree, NRCD 30, in 1972 [26]. Unfortunately, over the forty years of its existence, the Mental Health Decree (NRCD 30), was not implemented. Rather, since the early 1990s several unsuccessful attempts were made to enact a new mental health law. Before 2004, The Law Reform Commission (LRC) was involved in revisions of the 1972 Decree. It is surprising however that these earlier revisions including the Mental Health Law, 1990, were not enacted, not even during periods of constitutional rule [27].

The process that led to the passage of the Mental Health Act by Parliament in March 2012 was initiated in 2003. From 2004, financial and technical support was given by the Mental Health Department of the World Health Organization (WHO).The process of formulating and revising the legislation involved a series of consultations with a wide variety of international and local stakeholders. A new Mental Health Act 846 was passed in 2012.

\subsection{The implementation of the current mental health act of Ghana}

According to the Ministry of Health,eight per cent of all admissions to general hospital / clinic based psychiatric inpatient units and $2 \%$ of all admissions to mental hospitals were legally sanctioned involuntary admissions. The remaining patients are either voluntary or admitted against their will without the use of legislation but with proxy consent by their relatives, and that is still considered to be 'voluntary'. Ten to twenty percent of in-patients are restrained (mechanical and/or non-mechanical) or secluded [28].

Greater Accra Region had 7.23 times more beds, 4.28 times more psychiatrists and 4.44 times more nurses than the rest of the country despite only sixteen percent of the 24.2 million population of Ghana living in that Region. Most mental health services are in or near large cities [29].

Greater Accra has the most staff and treats the most outpatients per 100,000 of their population whereas Ashanti has the fewest and treats the fewest patients (per 100,000). Upper East and Upper West are not well supplied with staff but both treats a high proportion of their populations, particularly Upper East suggesting high efficiency and productivity in these regions [28]. There are currently about 1,887 staff working in mental health services. Sixty two per cent $(1,177)$ of the 1,887 are specifically trained in mental health and $710(38 \%)$ are staff working in mental health but not specifically trained in mental health [23].

Although there is no national organizational body for mental health, the responsibility for national organization of mental health services is vested in the Chief Psychiatrist as the national head who also serves to directly advise the Minister for Health on mental health. There is a focal person for mental health located in the Institutional Care Division of the Ghana Health Service, to coordinate mental health care in the Ghana Health Service institutions. The Chief Psychiatrist also coordinates planning and organization of mental health activities at the national level. At the regional and district levels, the Regional and District Coordinators of Community Psychiatric Nursing serve as the coordinators.

\subsection{Problems confronting mental health care in Ghana}

Several challenges still confront mental health care in Ghana. These challenges are grouped under organisational, financial, legal and judiciary as well as the role of the Commission for Human Rights and Administrative Justice (CHRAJ). These challenges are discussed in the following sections.

\subsubsection{Health system organizational challenge}

The Mental Health Services have by and large remained attached to their historical origins within the curative health framework [30]. The extension of psychiatric facilities to units within Regional and District Hospitals is consistent with the curative paradigm. Community psychiatry is viewed within this framework as 'outreach' services from psychiatric facilities. The application of public health principles to mental health services has not been tried.

The Mental Health Unit (MHU) is organizationally placed within the Institutional Care Division (ICD) of the Ghana Health Service. The offices are located in the Accra Psychiatric Hospital. From this location the MHU governs the three state psychiatric hospitals and operates a national community psychiatric nursing service [14]. Oversight for the regional psychiatric units is provided by their respective regional health administrations. Community psychiatric nurses are paid and supervised by their respective district health administrations. There is no operational link between the Directorate of Public Health in the Ghana Health Service (GHS) and the Mental Health Unit [31]. There is no organizational or structural representation of the MHU within the Ministry of Health hierarchy.

The low morale and dissatisfaction of mental health professionals and their perceived negative treatment within the Ghana Health Service over the years might have been a motivating factor in the formulation of the original version of the Mental Health Act of 2012 which proposed a Mental Health Service separate from the Ghana Health Service. This observation might have informed a view reported to 
have been expressed by a prominent psychiatrist that mental health professionals were 'misfits' in the Ghana Health Service (GHS) [32]. However the idea of a Mental Health Service separate from the Ghana Health Service was not adopted.

\subsubsection{Legal and judicial challenge}

The availability of a legal forum where people can go to seek enforcement or redress for the breach of their rights, trained health professionals and administrators, advocates to assist people in their representations, are necessary conditions for the implementation of the mental health act. These facilities will need to be put in place in Ghana as soon as possible. Indeed the congestion of the state psychiatric hospitals and consequent violation of the human rights of patients can be attributed in part to the failure of successive health administrators to implement the Mental Health Tribunal Procedures.

A few prominent human rights lawyers and NGOs, notably the Human Rights Advocacy Centre, are the visible advocates for the rights of persons with mental illness whose human rights have been breached. HelpLaw Ghana is another NGO/Charity established with the sole purpose to provide free services to the poor and less privileged in Ghana. However, the extent of their involvement with patients in psychiatric facilities remains uncertain [33].

The law faculties of the University of Ghana and Kwame Nkrumah University of Science and Technology, do not offer elective courses of study in health law hence lawyers trained in Ghana qualify without exposure to health law training, let alone mental health law. Without lawyers who are trained in health law to help interpret, advocate and enforce the mental health act, to protect patients' rights and implementation of the Act, the risk of non-fulfilment or breach of patients' rights will be acontinuos reality. The Act stipulates that the Mental Health Review Tribunals (MHRTs) are presided over by senior lawyers. In the earlier drafts of the Act, it was envisaged that the Mental Health Authority would be responsible for the regulation of the MHRTs. It has been suggested that as the MHRTs are quasi-judiciary in nature, their regulation should be from the Judicial Services and not by the Mental Health Authority. This arrangement if put in place would guarantee a higher level of independence and impartiality of the MHRTs.

In the Mental Health Decree, NRCD 30 1972, no provision was made for receiving and investigating complaints from detained patients. It might be reasonably assumed that the appeals process would take complaints into account or that the hospitals might have a robust grievance and complaints procedure. The Mental Health Act, which clearly places more emphasis on the patient, is more explicit in this regard and makes provision for complaints from detained patients to be heard and investigated. A high turnover of complaints should therefore be anticipated and prepared for. A review of enactments relevant to the mental healthcare needs to be undertaken to bring them in line with the mental health Act. This might result in consequential amendments. For example the decriminalization of suicide requires an amendment the Criminal code, 1960, Act 29.

\subsection{The ambiguous role of the commission for human rights and administrative justice (CHRAJ)}

It is common knowledge that the Commission for Human Rights and Administrative Justice (CHRAJ) receives and investigates complaints from and on behalf of patients who suffer from mental illness, particularly those on admission to various psychiatric hospitals. In this regard, it is not unreasonable to assume that in respect of receiving and investigating complaints, CHRAJ is the de facto Mental Health Review Tribunal.

In recent times, CHRAJ has undertaken an advocacy role in respect of Persons with Disability and the calls for the implementation of the legislative instrument for the Persons with Disability Act, 2006 (Act 715). A strong link between clause 72 of the Mental Health Act, which requires the Minister responsible for Social Welfare to make provision for the psychosocial rehabilitation and after-care services of mental health patients, including supervision, rehabilitation and vocational training, and clause 15 of the Persons with Disability Act; it requires that, as far as practicable, persons with disability shall be rehabilitated in their communities to foster their integration,would ensure that people with mental illness who become psychosocially disabled as a result of their mental disorder will benefit from the provisions of this enactment. Equally, the Rights of Persons with disability (clauses 1-15 of the Ghana Disability Act 2006) might be applicable to a proportion of the mentally ill who suffer psychosocial disabilities during the course of illness. It is not certain that the CHRAJ programme on the Human Rights includes the Rights of Persons with Mental Illness.

\subsection{Financial problems}

Mental Health financing should be re-examined systematically from broad variety of viewpoints. Mental health had a ring-fenced budget of $1.4 \%$ of total governmental health expenditure. It is not feasible for the health sector alone to bear the burden of mental healthcare costs. This expectation is also unrealistic 
given the constraints on the health budget. Careful mapping of potential sources of funding is the first step in ensuring that mental health care is not underfunded [25]. The Mental Health Act seeks to introduce several new components to mental healthcare delivery which would require an augmentation of the sector's financial base if it is to be workable. To this end, the Act proposes the establishment of a Mental Health Authority with a governing board and several departments to perform roles that are parallel to the Ghana Health Service. It also proposes the setting up of visiting committees in all ten regions to conduct periodic inspection of mental health facilities. If all these administrative bodies are to be adequately catered for, the meagre fiscal arrangement that currently exists may not be able to sustain the new regime, and may increase the resource going to the top management rather than the actual frontline patient care. This will burden the already overstretched national budget to work against the spirit of the Act.

Extending the mandate of some existing institutions and strengthening their capacity to deal with mental health related matters could curtail the financial burden, which might result from the creation of these new institutions. For instance, the role that the proposed visiting committees are to perform can in the interim be performed by CHRAJ conveniently performed in the short to medium term, by the Commission on Human Rights and Administrative Justice (CHRAJ). Siginificantly, health services cannot be run with this level of funding if rampant miscarriages of justice and costs due to compensation for such miscarriages are to be avoided.

Community-based care for people with mental disorders deceptively appears to be cheap but evidently not. Also, expansion of the logistical improvements that might be required to build the capacity of CHRAJ to undertake its new mandate might also improve the capacity of CHRAJ to perform its existing mandate [34]. Importantly, CHRAJ will provide informed, independent and objective oversight which an oversight body may lack, at least, in the first two areas.

\subsubsection{Social services challenge}

The present situation concerning the workforce and conditions of service of general social services in Ghana do not hold out much hope regarding the ability of the social services to provide adequate numbers of social workers well-skilled in mental health to support the implementation of the Mental Health Act [35]. Under the Act, psychiatric rehabilitation is not considered as a clinical issue for psychiatric services, but rather the duty of the Minister responsible for Social Welfare. The community-based rehabilitation programme in Ghana is mainly restricted to the needs of the physically disabled without acknowledgement of the provision for community rehabilitation needs of people with mental disability. Although the definition of disability as defined in the Persons with Disability Act includes people with mental disorders, mental disability is not addressed within the disability framework in Ghana. Therefore, there is a need to address this apparent anomaly and integrate mental health into the community-based rehabilitation within social services in Ghana. At a higher organisational level, cross or reciprocal representation between the National Council of Persons with Disability (NCPD) and the Board of the proposed Mental Health Authority might be mutually beneficial in advancing social care provision and community rehabilitation needs for people with mental disability.

\subsubsection{Poor mental health service since 1900}

The Komfo Anokye Teaching Hospital is the main government hospital located in Kumasi which attends to the health needs of people in the Ashanti Region of Ghana and the rest of Northern part of Ghana. The hospital is mandated to provide specialist clinical care services, train medical students and undertake research into emerging health issues in Ghana. The hospital has several departments including the paediatric, surgical, maternal, psychiatry, among others. The apparent decentralised nature of the various departments of the hospital ensures the effective of specialised health care services. However, the hospital serves mainly as a referral hospital, hence cater for emergency and critical conditions. The psychiatry department of the hospital is by far the only government mental health facility serving the whole of the northern part of Ghana, including Ashanti, Brong Ahafo, Northern, Upper East, Upper West and part of Volta Region. KATH is the second largest referral hospital in Ghana. At the time of research, the head of the Psychiatric Unit of KATH was Dr. Gordon Donnir. He lamented greatly about the state of the Komfo Anokye psychiatric unit. He once lamented about the intense pressure on the facility to provide mental health service to the increasing population in Kumasi and its environs. According to him, the prevalence of mental health diseases in the country is on the increase and high incidence of drug related mental health cases are being reported at the psychiatric facility at the hospital. This he indicated has hampered the hospital's ability to fulfil its mandate of providing specialist clinical care for all persons in the country [36].

The general situation in Ghana is also dire. In 2007, the World Health Organisation reported that about three percent of the total population were suffering from serious mental disorders, whiles about 10 percent of Ghanaians suffered from moderate to mild mental disorders [37]. While the burden of mental 
health care is a public health concern worldwide, there is a significant gap between the level of mental health needs and the availability of quality services to aptly address these needs. In Kumasi and to a greater extent, the whole of Ghana, mental health is often given the lowest health priority by authorities and this sometimes deepen the stigma and discrimination faced by people with mental problems.

In Ghana, persons with mental disorders, mental health services, mental health professionals and even the very concept of mental health receive negative publicity and are stigmatized and discriminated against in spite of growing evidence of the importance of mental health for development. For this reason many people refuse to work as mental health professionals. The Komfo Anokye Teaching Hospital currently has only three resident psychiatric doctors, six consultants and nineteen psychiatric nurses. Generally, in Ghana, there are fewer than necessary psychiatrists, psychiatric nurses, clinical psychologists, psychiatric social workers and occupational therapists. It is estimated that each psychiatrists in Ghana is burdened with about hundred thousand mental health patients [38].

The field survey for this study has revealed that the mental health care service in Ghana is faced with two main challenges. This problem includes the problem of inadequate facilities which often results in congestion at the various psychiatric hospitals. Currently, there are only twelve beds (six males and six females' beds) at the psychiatry unit of the Komfo Anokye Teaching Hospital. According to a nurse respondent I have anonimised as Marie, "the congestion of patients ward and their living conditions are human rights violations in and of themselves" [39].

Another problem of health care service in the study area had to do with inadequate mental health professionals to cater for the health needs of the mental health patients. Dr. Donnir indicated that, "the stigma attached to mental health in general does not encourage people to take up a profession in mental health". Many of the psychiatric nurses are exposed to danger of being harmed by aggressive patients. For this reason, mental health officers are unable to give adequate care to their patients. It is clear that the health and wellbeing of the mental health staff, that is, doctors and nurses in particular are jeopardised from time to time.

The mental health section of KATH in particular pays attention to the spacing of beds and effective care of the mentally ill, the reality is that many more patients are turned away when they come to the hospital to seek mental health care. Apart from the Out-Patient Department (OPD) cases that are handled by the unit on daily basis is huge. Nurse Marie revealed that, several patients who out to be admitted are turned away by the unit because of lack of space. She stated that, "we have only six beds at the both male and female wards... in case there is a patient with serious mental health need and the place is full where do we keep him... we have to turn him away... it is not our fault'[40].

The psychiatry unit is found next to the hospital's pharmacy. The space available to the Unit was found to be woefully inadequate. Nurse Mary, pointing to the OPD stated that "sometimes we serve as many as one hundred and twenty patients... these people often have to wait at the small space allocated to OPD patients... Sometimes patients are made to stand at the corridor because of lack of space at the OPD” [40] The main challenges confronting mental health service delivery at Komfo Anokye Teaching Hospital were thus found to be inadequate space and lack of psychiatric health professionals to attend to the needs of patients.

\subsubsection{Legislations on mental health that have been enacted in Ghana from 1900 to 2012}

In order to do a proper analysis of the various legislations on mental health that have been enacted in Ghana from 1900, the researcher conducted a documentary analysis of the mental health legislation using the World Health Organisation Checklist for Mental Health Legislation. This checklist is designed to assess the content and development of mental health legislation based on certain pertinent criteria [41]. As explained in section 2.1.2 of this study, three different legislations on mental health have been passed in Ghana. However, the researcher only had access to two of such legislations during the field survey. Thus the researcher evaluated the 1972 Mental Health Decree and the Mental Health Act of 2012.

Section 12 of the Mental Health Decree of 1972 made provision for the admission of suspected mental health patients against their will (involuntary admission). Even though such persons had a right to appeal provided for them in the provision (Section 12b). Additionally, the Mental Health Decree of 1972 provided accreditation of professionals and facilities, enforcement of judicial issues for people with mental illness and mechanisms to implement the provisions of mental health legislation.

The mental health decree was juxtaposed with the WHO Checklist on Mental Health Legislation. This comparison exposed various shortfalls in the mental health decree. Even though the WHO checklist came at a later time, it became the benchmark by which all mental health legislations of all WHO member countries were to be measured. Among some of the shortfalls identified per the review included the apparent neglect to the provisions of the protection of human rights of the mental health patients. The law for instance did not include the right to humane treatment for the mental health patients. They also lost basic rights like the protection of privacy and confidentiality, the rights of carers and families of the mental health patients to 
have access to their relatives. Additionally, the mental health patients could be detained without their informed consent. The mental health decree had little regard for the protection of the mental health patients. It rather saw the mental health patient as a danger to the rest of society. He had to be apprehended by any means. This rather legitimised the use of force to restrain mental health patients. Several evidence were found during the field survey of how mental health patients under both institutional care and traditional health care were either secluded or restrained.

Even though the mental health decree was institution oriented with no consideration toward community mental health and rehabilitation of the mentally ill, there was no provision for adequate facilities in the general hospitals. The mental health decree also did not make provision for the care of the mentally ill outside the psychiatric hospitals in areas like the traditional healing centres and spiritual homes.

In fact the decree made little provision for the protection of the rights of the vulnerable groups such as minors and women who may be mentally ill. Additionally, funding for mental health is a major challenge. The decree did not make provision for financing of mental health service in the hospitals. According to Dr. Osei, who is a clinical psychiatrist, less than one percent of the budgetary allocation to the ministry of health is dedicated to mental health services [42]. The mental health service in general is so under-resourced that the patients do not feed three square meals a day. Sometimes they eat once a day and when they are fortunate they get a second meal.

The obvious under-financing of this sector of health care also affects access to drugs for patients. According to Baaba Blankson, "the hospital is unable to buy the necessary psychotropic drugs for the patients". She asked rather rhetorically that "when a patient is being aggressive and you do not have tranquilizer to keep him sober what can you do... All you do is to run away from the ward and hope by some miracle he will become sober [43]." The mental health draft was only a paper document with form but had not substance. When reviewed in the eyes of the WHO checklist of mental health legislation, the decree lacked the ability to bring respite to the suffering of the mental health patients. Rehabilitation was rather left out of the options and mentally ill people were treated as though mental illness was a terminal disease which could never be cured. The law was such that, there was no provision made for the involvement of users of mental health services, families and carers in mental health policy and legislation development and planning. Once a person is detained, he was treated as though he was in prison without any right or dignity.

The mental health act of 2012 however was formulated with the guidance of the WHO mental health legislation checklist; hence this law took care of very important human right issues that were ignored by the mental health decree of 1972. However, whilst some respondents felt that the new mental health act addressed many of the deficits in mental health care in Ghana, including regulating traditional and faith healers, and addressing stigma and social exclusion, some expressed scepticism as to whether there were adequate resources, as well as the political will, to implement the law. A repeated theme among participants is that there is a gap between policy or legislation and its implementation in practice due to lack of political commitment or resource constraints. One respondent, noted retorted that, "in Ghana, we have fine laws but the implementation is often poor. In fact when you look at the mental health act, you might think Ghana has perfect health system. Everything has been catered for in the law. There is not much education on mental health nursing for the ordinary Ghanaian, you understand? Even policy implementers, people are not really well informed about mental health programmes. For this reason even though we have the mental health act addressing some of the human right abuses, the mentally ill person does not have the capacity to claim his or her right" [41].

The Mental Health Act adopts a human rights approach to mental health, in accordance with the UN Charter on Human Rights and international consensus on the health care needs of a person with mental disorder. The Act aims to prevent discrimination and provide equal opportunities for people with mental disorder. It addresses many of the weaknesses of the Mental Health Decree, providing for a mental health authority, a mental health review tribunal, and the protection of the rights of people with mental disorder, including the principle of the least restrictive environment and the right to information and participation.

The law promotes the decentralisation of mental health services and community mental health care and regulates traditional and faith-based healing practices. A missing element of the law, identified by the WHO checklist is that although there is mention of the sources of funding for the mental health authority, there is no stipulation on minimum funding requirements for mental health services. For this reason the current Act also faces major challenges including inadequate financing, stigma and the absence of logistical support to implement the policy. Dr. Osei intimated that, "there is an absence of framework for mental health service. The manpower resource available is obviously limited, because not too many specialists are in that area. Very few people are interested in that. The stigma attached to the mental health definitely is also a barrier. There are barriers in terms of funding for various services" [42]. He further stated that, "not all the people are interested in mental health, especially most of the public health doctors, people who study public health, you mention mental health and you are just ignored because you're not dealing with good people or 
normal people, so they try to stigmatize the institution". These are obvious challenges that must be overcome in order to effectively implement the mental health act of 2012. There is the need for inter-sectoral collaboration in order to fully implement the mental health Act of 2012. Awareness creation and adequate funding are key in the effective implementation of the Act in order to protect the human rights and dignity of mental health patients.

\subsection{The implementation of the current mental health act of Ghana}

On March 2012, Ghana jumped a siginifcnt hurdle in mental healthcare. The Mental Health Act (2012), Act 846 was passed to replace the defunct Mental Health Decree of 1972. The passage was seen as a major achievement in the struggle for the promotion of the fundamental human rights of all Ghanaians including persons with mental disorders. This was after forty years of the operationalisation of the mental health decree which curtailed individual liberties and freedom of the mentally ill.

The law made provisions for the appointment of the Hospital Director and Clinical Coordinator psychiatric of all psychiatric hospitals. The body mandated by law to appoint the Hospital Director and Clinical coordinator was the Governing Board of the Mental Health Authority instead of the president, as existed in the previous decree.

"On the issue of seclusion and restraining of mental health patients, the current law, Act 846, abolished the unlawful detention of mental health patients. This was withdrawn for reasons of practical impossibilities and the need not to legislate the practice. The framers of the law believed that personnel of the facility should be given some discretion to enable them assess each situation and apply the best procedure for any given situation" [42].

In terms of employment rights, Dr. Osei explained that, the Mental Health Act implored the employers to provide assistance to employees presumed to be suffering from mental illness. As a result Clause 63 of the mental health act speaks extensively to the employment rights of the mental health patients. The new Act also suggests the establishment of the Mental Health Fund which is tasked with the responsibility of managing all funds and raising funds using a number of stated avenues. The principal objective of the Mental Health Fund is to provide financial resources for the care and management of people who suffer from mental illness.

Even though, the provisions in the Mental Health Act (2012) might be regarded as promoting the fundamental human rights of mental health patients, its implementation has not always been smooth. The next sub-section looks at specific areas of the implementation of the mental health act.

\subsubsection{Financing mental health services in Ghana}

Section 88 of the mental health act state emphatically that "mental healthcare is free". It goes further to explain that a person suffering from a mental disorder with a physical condition is entitles to free health care under the National Health Insurance. The financing for free health care for mental patients is derived from multiple sources of revenue including moneys approved by parliament; money derived from fees; donations, grants and gifts; moneys derived from investments and any other moneys that are approved by the Minister responsible for finance.

Despite the general provision in section 88 of the Mental Health Act, the health care service available for the mentally ill is not implemented in accordance with the full provision of the law. For instance, whilst the Sections 21, 22, and 23 of the current law states emphasizes the commitment to a decentralized health care and the training of mental health professionals, the irregular flow of fund into the sources of revenue stated above, particularly at the regional and district levels means that mental health policy remains far removed from the reality of the practice. Free mental health service provision only exists on paper. The reality is that mental hospitals are poorly resourced in Ghana. The law is well formulated but cannot be said to be on the list of the priorities of Ministry of Health of Ghana. Dr. Osei explained that, "there are a lot of lip service in terms of the commitment to the full implementation of the mental health act. Its implementation has been faced with serious financial and logistical challenges."

Nurse Marie also stated that, mental health patients are required to pay GhC 36 for a psychotic medicine. This was supposed to be free according to the mental health act. The implication of this response is that, even though the ministry of health has identified mental health services as essential in the health care delivery system, very little has been done to resource the sector, both at the level of the institutions and at the community level.

Miss Marie indicated that, "having worked with the mental health unit for a while, I have come to the realization that the sector is highly handicapped in terms of finances and the institutional support to run the mental health institutions and so I can say it in not easy for the hospital administration to comply with the full provisions of the law. It is highly difficult to integrate mental health into primary health care. The Komfo Anokye Teaching Hospital has designated 15 beds to mental health and a dedicated ward. So in terms of the 
implementation of the mental health Act, I would say the hospital administration is really trying even though little success has been achieved due to the financial difficulties facing the sector".

Several news items in Ghana on mental health care since 2012 reflect an under-financing of Mental Health Service in Ghana. It is argued that mental health care delivery is gradually failing just after four years of the enactment of the mental Health Act. Whilst there is recognition that some elements of the law are being implemented, the failure to allocate adequate resources prevents their full implementation. Various media report concerning the implementation of the law shows a gloomy picture of the mental health delivery in Ghana. For instance, in a media report by the Ghana News Agency, on $9^{\text {th }}$ October, 2015, Mr Peter Badimak Yaro, the Chief Executive Officer of Basic Needs-Ghana, noted that inadequate supply of psychotropic medicines continued to plaque effective mental health service delivery in the country [44]. In another news article on 26 ${ }^{\text {th }}$ February, 2016, a news item on www.peacefmonline.com titled "Ghana experiencing acute shortage of psychiatric medicines", the Regional Co-ordinators of Mental Health Services in Ghana lamented on severe and persistent shortage of essential psychiatric medicines for mental health patients in the country during 2015 [44].

This shortage affected mental healthcare delivery of the already poorly supported Mental Health Service. For that matter, patients and facilities had no option but to resort to the open market, where prices of such medications were very expensive. Additionally, the situation forced most patients and their caregivers to refuse review visits since they could not afford their medications, and in some cases not get it at all. In a review report of mental health delivery in Ghana for the year 2015, Dr. Akwasi Osei, the CEO of the Mental Health Authority indicated that "the inadequate supply of psychotropic medicines nationwide, including at regional and community levels, was a major challenge of the authority in ensuring quality mental healthcare delivery. The reason for the shortage was attributed to lack of funds to support service delivery in the sector.

Additionally, some respondents questioned the rational for making mental health free of any charge when the government cannot even afford to provide the needed medicine. Dr. Donnir stated that "the free mental health service in Ghana cannot be sustained in the long term... it only encourages families to abandon their relatives at the psychiatric hospitals, relieving themselves of all the financial responsibilities of their relatives. According to Dr. Osei, some fees must be charged to offset some of the huge cost of caring for the mentally ill. In a statement, he remarked that “... we are a poor country and cannot continue to provide free mental health services in the country. Even in the advanced countries, people contribute something, patients or their relatives; contribute something because the government alone will not be able to pay. The drugs alone are very expensive; we can't buy the drugs, give it free, buy food, and give it free. I therefore think that they should look at the funding and take a more pragmatic decision towards the effective implementation of the mental health act'.

Mr Yaro noted that "the absence of a Legislative Instrument on the Mental Health Act (Act 846) remained a procedural challenge to the effective implementation of the law" [43].

\subsubsection{Prioritization of mental health services in Ghana by the Government of Ghana}

This section of the study examines whether mental health is prioritised by government. To determine whether mental health service is a top priority of the government of Ghana, it is important to measure the amount of money dedicated to the sector in relation to other sectors. Additionally, it is important to critically assess the condition of the main psychiatric hospitals in Ghana. This will give a fair idea of government's commitment to mental health delivery in the country. The next section looks at the financial allocation to the mental health service.

\subsubsection{Financial support for mental health service post mental health act of Ghana}

In 2014, the Ministry of Health published its Medium Term Expenditure Framework to regulate health care delivery in Ghana. The fifth objective of the framework states that the Ministry of Health seeks to "strengthen institutional care including mental health service delivery". Meanwhile, no financial allocations had been made by the central government through the ministry of finance to support the delivery of mental health services. In a media report carried out by ww.myjoyonline.com on the $24^{\text {th }}$ of February, 2016, titled "mental Health Authority has not received a penny from government", Dr. Samuel Ohene, who is the Head of Psychiatry at the Korle-Bu Teaching Hospital, reported that "not a single penny from government has gone into the Mental Health Authority since it was set up in 2013". He complained that, "after government passed the Mental Health Act, 2012 (Act 846) and named a Board in 2013, it has gone to sleep when it comes to funding the operations of the Authority". The situation was so bad that even office space for the operations of the authority was not provided. Dr Ohene intimated that "not even the office building of the Authority was provided for by government. The only source of funding for the Authority's activities is the DFID" [42]. I infer that individuals like Dr. Ohene and several other mental health professionals believe that respective governments and political leadership in particular have not taken mental health services seriously. 
To add to this, one of the survey respondents, Marie, stated that, "we get some shortages. We have only 22 drugs, 22 approved essential drugs. In most cases, we don't have even at least three- quarters of the drugs available. Last year for example, the government was supposed to purchase about 1.2 Million Cedis worth of drugs for us; they were able to purchase only 430,000 Cedis the rest never came. So we kept on writing and made substitution of drugs. That is the problem, that we have... we never get self-sufficient in drugs supply."

She explained that when medication is unavailable at the hospital pharmacies and clinics, patients must purchase the necessary medication on their own: "the drug flow is low; with the rate at which we get the drugs is still the problem. Sometimes, it comes and the people keep on increasing, I think they have limited their rate of supply, so now the people are more than the drug that is usually requested to cover specific period. The drugs we purchase from outside sources is quite expensive. Patients find it difficult buying from pharmacies instead of receiving supply from the hospital. Some don't even have the money to go and buy". For this reason, the psychotropic medication which should be free in principle is bought by the patients in reality on the open market at exorbitant prices.

In terms of specific budgetary allocation, it was difficult to obtain specific figures showing the expenditure for mental health in Ghana. However, by convention, 6.2 percent of the health care budget of the Ministry of Health is dedicated to mental health. It was not easy to obtain precise figures for mental health expenditure in Ghana. $6.2 \%$ of the health care budget of the Ministry of Health is dedicated to mental health. It was revealed from the Medium Term Expenditure Framework (MTEF), that some moneys are routinely sent to the micro level directly from the ministry of finance as part of the de-centralisation process, without the knowledge of some national and regional level authorities [44].

The majority of the budget for mental health (nearly 80\%) is allocated for the maintenance of the three psychiatric hospitals. Despite this, funding for the psychiatric hospitals was described by the respondents as 'woefully inadequate'. Dr. Donnir, reported that funds are quickly absorbed in meeting the basic needs of the patients, and recalled that the psychiatric hospitals had recently run out of sufficient funds to feed the patients. He reiterated that there are few resources remaining to fund psychosocial and rehabilitative interventions in the hospitals.

At the regional and district levels there is no allocated budget for mental health. Since the psychiatric hospitals are funded directly from the Mental Health Unit at the national level, the psychiatric hospitals are virtually autonomous from regional health administration. This means the psychiatric hospitals are not integrated into regional health structures. With the advent of psychiatric wings in the regional hospitals, there is a need for closer collaboration between regional and district levels in the administration of mental health care. As revealed by Dr. Donnir, at KATH, some level of integration between psychiatric and primary health care services is occurring; however this needs to be strengthened. He hinted that, '....our allocation comes directly from the Ministry of Health so it's like the regional level, they don't have control over us, and so they stay away from us. But this time we should work together. We should participate in their activities because they are important. We are collaborating with the regional and the district directors and then participating in their activities" [37].

The discussions above have revealed that the allocation of financial resources to the mental health units by the central government is woefully inadequate and irregular. This leads much to be desired and affects the effective implementation of the mental health act of Ghana. This shows clearly, government's dereliction to making healthcare accessible to the mentally ill.

\subsubsection{Conditions of psychiatric hospitals in Ghana}

The main psychiatric hospital in Ghana is the Accra Psychiatric Hospital, also known as the Pantang hospital. There are three sources of funds available to the Accra Psychiatric Hospital. These sources include the government, internally generated funds, and donations. In 2012, financial resources to Pantang amounted to GHC 1,941,385.67. Out of this amount, 35 percent was from the government. Donations from foreign entities amounted to 57 percent of funding and internally generated funds from drugs and services represent 8 percent of annual income. The hospital has however been running in debts every successive year. In 2015, its debt stood at GHC 977, 448.05. As a result of funding challenges, the Accra Psychiatric hospital has only 60 to 80 percent of the medicine they need.

At Pantang Hospital, the inpatient section of the hospital consists of nine wards (two of which are VIP wards) with 50 beds, and any extra patients sleeping on thin mattresses. The VIP wards, which cost money to stay in, do not necessarily receive better treatment, but the rooms are less crowded (possibly single), the food is better quality, and there is air conditioning. At the Accra Psychiatric Hospital there are 3 infirmaries and 23 wards in total; 16 are male, six are female, and there is one children's ward. One ward each is reserved for the male and female wards for geriatric cases. 
The largest special ward is reserved for forensic court cases and more aggressive males, 234 of them in total, though the official occupancy is only 60 for that particular ward. The largest female equivalent ward has 110 patients but the average number of patients in a ward is close to 50. Because there are only 500 beds (3-inch thick foam mattresses) and currently 1,000 inpatients at the Accra Psychiatric Hospital, the congestion leaves 500 patients to sleep on the concrete or on thin mats either inside or outside. There are no fans or air conditioning either. The ones forced outside without insecticides or mosquito nets are subject to the mercies of the weather during the day and the disease carrying mosquitoes at night.

These patients also share their space with ants, cockroaches, and rats. Though there is tap water available, drinking it is not encouraged, so patients have to pay a small fee for filtered drinking water. Water flows through the pipes only twice a month so there is not enough water or disinfectants to properly clean the estate. In addition to that, the hospital is constantly buying water to fill tanks and filtered water to give to patients. Patients eat three low quality meals a day that usually consist of rice, adding up to GHC 3.60 a day. Uniforms are not provided so the patients are free to wear their own or donated clothes, however it is a common and disturbing sight to see people running around stark naked or half naked with tattered clothes hanging loosely off their body. The congestion of patients and their living condition are human rights violations in and of themselves. Records are kept analogue, in a room full of bulging, tattered folders; though they are trying to digitize the system, it is difficult with only 15 of the necessary 100 computers. There is also an intercom that works $80 \%$ of the time. The building, initially built as a prison and not as a hospital, is 100 years old, which makes it gruelling to clean and maintain. There is asbestos in the roofing, sewage system pipes have broken, and the buildings look like a rundown dog pound instead of a pristine, sanitary hospital. The description of the main psychiatric hospital of Ghana is not vastly different from the conditions of the two other remaining facilities. What needs to be done to improve the conditions of the mental health facilities by the government has not been done it is obvious the government has not prioritised mental health in Ghana.

\subsection{Challenges confronting mental health services in Ghana 3.8.1. The manpower challenge}

A critical review revealed that there are currently eleven psychiatric doctors in Ghana. Four of these doctors are at the highest level of certified consultants; six of them are retired but work in private clinics. An efficient system can only be run on relevant manpower. The mental health service delivery lacks the relevant manpower to ensure its efficiency. The enormous nature of work requires the engagement of more psychiatrists in the country. According to Dr Osei, the current demand for psychiatrists stands at eighty (80). This means there is a shortage of about 69 psychiatrists to augment the delivery of mental health in Ghana.

Several Ghanaian mental health professionals go overseas seeking better pay and better conditions. Shockingly, there are currently twenty Ghanaian psychiatrists practicing in the U.K. when there are only eleven psychiatrists in Ghana. There are only 600 Psychiatric Nurses presently working when there should be at least 3,000 in order to care for most of Ghana's mentally ill. Psychiatric Nurses train at either Pantang or Ankaful, and complete one year of general nursing and two years of specialized psychiatric nursing. Clinical psychologists are regrettably not even recognized by Ghana's Ministry of Health, and any clinical psychologists working at a Psychiatric Hospital have to be listed under another title on the payroll.

\subsubsection{Stigmatisation and societal neglect of mental health patiens}

These psychiatric hospitals have a problem with patients overstaying because there is not enough manpower to frequently evaluate each patient's progress, the courts do not come for them, or the patients live very far from their family. In some cases, the families forget to inquire about their relatives or refuse to pick them up due to the hospital's distance from their village, or the families can no longer be reached. Moreover, the associated stigma results in a great deal of patients being abandoned by their families upon admittance into the psychiatric hospital. Mary Amoah recounted some heart wrenching pattern common to the children's ward. She explained that some parents giving spurious phone numbers and addresses to the hospital so that they can no longer be contacted in reference to their child. Dr Donnir stated that only twenty percent of patients at the Psychiatric Hospitals have relatives who care enough to occasionally visit. Patients who have regular visits are mainly those whose cases are considered as minor.

\subsubsection{Misunderstanding of the causes of mental diseases}

There is misconception in Ghana about the causes if mental illness in Ghana. The predominant perception about the causes of mental illness is evil spirits. There is the belief that supernatural forces, evil spirits, curse, bewitchment, or planted juju cause mental illness. A report by Basic Needs Ghana, found that most Ghanaians believe that the mentally ill cannot be productive in a society and that the reason they are mentally ill is because they are cursed or have offended a deity. Ghanaians view mental illnesses differently than physical illnesses because physical illnesses are tangible, easy to comprehend, and are generally easily 
treated with the right medication. People are more likely to attribute supernatural causes to things they do not understand. The average Ghanaian's view is the same for both the mentally disabled and the mentally ill. Though epilepsy is a neurological condition and not a mental illness, people with epilepsy are also considered to be mentally ill in Ghana because they share the same stigma and because they have been historically treated by psychiatrists due to the lack of neurologist.

\subsubsection{Lack of political will to fully implement the mental health act}

Dr Osei cited lack of political will as one of the major challenge confronting the mental health delivery. Politicians in Ghana do not want to give attention to mental illness, a sickness with low morbidity, when high fatality conditions grab more national and international attention. Because of this and its stigma, mental health care receives little donations from charities. For that matter, they do not make resources and funding available to psychiatric hospitals. The belief in superstition also deprives the mentally ill in Ghana of sympathy and compassion. This combination of ignorance makes the mentally ill vulnerable and exposed to human rights abuse. Thus, the government has not prioritised mental health delivery in Ghana.

\section{CONCLUSION}

This study has been conducted to review the mental health service in Ghana from the 1900s to date. The study concluded that, as early as 1888 , efforts were made by various governments to legislate the provision of mental services in Ghana. However, these legislations have not always protected the rights and interest of the mentally ill. The first two legislations rather infringed on the fundamental human rights of the mentally ill. Both legislations insisted on involuntary confinement of the mentally ill. The mentally ill were treated as though they were prisoners. The enactment of the current law however, brought some hope to the mental health practitioners. This hope was however dashed when funds were not made available to the Mental Health Authority. Currently the mental health service available to the mentally ill is poor. There is the need for government to prioritise mental health service in Ghana in order to overcome the various challenges confronting the sector. There is the need for the Mental Health Authority to work on a Legislative Instrument (LI) for Mental Health Act 846. There should be a framework by the authority, on how the funds allocated to the Mental Health Fund should be managed to support mental health care. Key directors should be appointed to co-ordinate the various aspects of mental healthcare delivery, including the efficient supply of medicines. That aside, the board of the mental health authority must ensure enhanced and persistent engagement with pharmaceutical companies for the local manufacture of some psychiatric medicines. There is the need for increasing budgetary allocation and training of more psychiatric nurses and physicians to meet the health needs of the mentally ill in Ghana.

\section{REFERENCES}

[1] WHO, "Prevention of Mental Disorders: Effective and Policy Options," World Health Organization, Geneva, 2004.

[2] World Health Organization, "Nations for Mental Health: Final Report," Mental Health Policy and Service Development, Department of Mental Health and Substamnce Dependence.

[3] Prince M., et al., "Global mental health:no health without mental health," The Lancet, vol/issue: 37(8), pp. 87-102, 2007.

[4] Osei A., "Pass the mental health bill now," Chief Psychiatrist of the Ghana Health Service, Graphic Ghana, 2008.

[5] Ibid, pp. 23-27.

[6] Ministry of Health, "Ghana Health Survey," Government of Ghana, Accra, 2013.

[7] C. C. Adomakoh, "Mental Health Patients, A Castle Road Profile," Ghana Medical Journal, vol/issue: 2(1), pp. 65$71,1972$.

[8] G. Tooth, "Studies in Mental Illness in the Gold Coast," London, H.M.S.O, 1950.

[9] M. J. Field, "The Search for Security, An Ethno-Psychiatric Study of Rural Ghana," London, Faber and Faber, 1960.

[10] U. M. Read and V. C. K. Doku, "Mental Health Research in Ghana, A Literature Review," Ghana Medical Journal, vol/issue: 2(46), pp. 29-38, 2012.

[11] R. Ormston, et al., "The Foundation of Qualitative Research," in J. Ritchie, et al., "Qualitative Research Practise(ed)," Los Angeles, SAGE, 2013.

[12] U. Flick, "An Introduction to Qualitative Research (4th Edition)," London, SAGE, 2009.

[13] M. D. LeCompte and J. J. Schensul, "Analysing and Interpreting Ethnographic Data," California, Alta Mira Press, 1999.

[14] U. M. Read, et al., "A situation analysis of mental health services and legislation in Ghana: challenges for Correspondence," African Journal of Psychiatry, vol/issue: 13(1), pp. 99-108, 2010.

[15] Mental Health Policy, "Mental Health Legislation and Human Rights," World Health Organization, 2003. 
[16] P. E. Tawiah, "Stigma and Discriminations Suffered by Mental Patients and Their Caregivers in the Ho Municipality of Ghana," University of Ghana.

[17] A. Osei, "The New Mental Health Act, Key Provisions and Implementation issues," pp. 1-31, 2012.

[18] O. A. Fournier, "The Status of Mental Health Care in Ghana, West Africa and Signs of Progress in the Greater Accra Region," Berkeley Undergraduate Journal, vol/issue: 24(3), pp. 8-32, 2011.

[19] P. B. Asaante, "Mental Ilness in Ghana," Msc Thesis, 2009.

[20] Doku V. C. K. and J. A. Wakame, "Implementing the Mental Health in Ghana: Any Challenges Ahead?" vol/issue: 46(4), 2012.

[21] H. Kofie and M. Montana, "The Mental Health Bill: Its Contents and why it should be passed without any further delay," Mental Health Society of Ghana, 2012.

[22] Mental Health Improvement for Nations Development, “A Very Progressive Mental Health Law," Accra, 2007.

[23] Op cit, Osei, pp. 12-14, 2012.

[24] Op cit, Asante, pp. 2, 2009.

[25] E. B. Foster, "Forensic attitudes in the delivery of mental health care in Ghana," Ghana Medical Journal, vol/issue: 10(1), pp. 52-55, 1971.

[26] Law Reform Commission, "Mental Health Law," Ghana, 1990.

[27] Ministry of Health, "Mental Health Profile," Ghana, 2013.

[28] Ministry of health, "The Mental Health System in Ghana," Kintampo, 2013.

[29] Forster E. B., "A historical survey of psychiatric practise in Ghana," Ghana Medical Journal, vol. 1, 1962.

[30] Asare J. B., "Mental Health in Ghana," Ghana Medical Journal, vol/issue: 35(3), pp. 105, 2001.

[31] Public Agenda, "Mental Health Practisioners Kick Against Ghana Health Service," HelpLaw Ghana, 2012.

[32] Ofori-atta, "Read Ae-nglibise \& Funk," 2008.

[33] Laird S. E., "African Social Services in Peril, A study of the Department of Social Welfare in Ghana under the Highly Indebted Poor Countries Initiative," Journal of social work, vol/issue: 8(4), 2008.

[34] G. Donnir, "Mainstream Psychiatric Care into Health Care Delivery," KATH, 2015.

[35] World Health Orgaization, "Mental Health improvements for nations: Country summary series," Ghana, 2007.

[36] A. Osei, "Pass the mental health bill now," Chief Psychiatrist of the Ghana Health Service, Graphic Ghana.

[37] Interview with Dr. Gordon Konnir, senior psychiatrust at the komfo Anokye Teaching Hospital, Kumasi, Interview took place at his office on $21^{\text {st }}$ april, 2016 at $10 \mathrm{am}$.

[38] Interview with Nurse Mary Amoah of the Komfo Anokye Teaching Hospital on 22 $2^{\text {nd }}$ april,2016 at 2pm

[39] WHO, "WHO Resource Book on Mental Health, Human Rights and Legislation," World Health Organization, Geneva, 2005.

[40] Interview with Baaba Blankson, a registered psychisatric nurse at KATH on the $22^{\text {nd }}$ of April,2016 at $2 \mathrm{pm}$ at the psychiatry unit.

[41] Ghana newsagency.org/health/minister worries about under-funding for mental healthservices, Accessed from $\mathrm{http}: / / \mathrm{www}$.ghananewsagency.org/health/minister-worries-about-under-funding-for-mental-health-services on $22 \mathrm{nd}$ May, 2016

[42] P. B. Yaro, The Chief Executive Officer of Basic Needs-Ghana.

[43] S. Ohene, "Mental Health Authority has not Received a Penny from Government," Accessed from http://www.myjoyonline.com/news/2016/february-24th/mental-health-authority-has not received-a-penny-fromgovt-dr-ohene.php on 02/05/2016

[44] Ministry of Health, Ghana, "Medium Term Expenditure Framework ( MTEF) Programme Based Budget Estimates For 2014," Accra, Ministry of Finance, 2016.

\section{BIOGRAPHY OF AUTHOR}

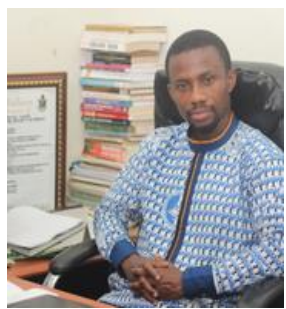

Samuel Adu-Gyamfi is the first trained social historian of medicine from the Kwame Nkrumah University of Science and Technology. His research interests include: Health policy, public health history, environmental history, integrative medicine, science and Technology and development. He is a Senior Lecturer at the Department of History and Political Studies of the Kwame Nkrumah University of Science and Technology. The author has over fifty publications that focus attention on health policy, public health history, education and development among others. 